\title{
An advanced gas-solid flow engineering model for a fluidized bed reactor system
}

\author{
D. Mao \& M. Tirtowidjojo \\ The Dow Chemical Company, Freeport, TX, USA
}

\begin{abstract}
A literature survey shows that there are two approaches to mathematically describe gas-solid two-phase flow and reaction in the fluidized bed reactors. One approach is a very simplistic engineering reactor model, and the other approach is based on a rigorous Computational Fluid Dynamic (CFD) model. Despite significant progress on numerical methods, CPU capacity and performance, and theories describing gas-solid flow, CFD based reacting flow modeling is far from being a routine tool for designing new reactors. Thus, simpler reactor models are still the main method for providing guidance for fluidized bed reactor design and optimization. However, traditional reactor models have considered too many simplifying assumptions that create inconsistencies in the governing equations of the boundary conditions such that it can result in erroneous prediction. In the current paper, an advanced gas-solid two-phase engineering reactor model has been developed for flow, heat transfer and reaction in the riser reactor of a circulating fluidized bed system. In contrast to CFD, this model can use as input parameters the hydrodynamic information obtained from published literature or experimental measurement such as axial and radial profiles for solid volume fraction, gas velocity and gas dispersion coefficient. While the hydrodynamics can be as accurate as measured, this advanced engineering reactor model is also coupled with either simple power law or the most rigorous kinetic models that involve elementary reactions. In this way, we can extract heterogeneous reaction kinetics from pilot plant or production reactor data directly. Model validation with pilot plant data and tracer data for a riser reactor will be presented and the short falls of traditional treatment of engineering fluidized bed reactor models will also be discussed.
\end{abstract}

Keywords: fluidized bed, gas-solid two-phase flow, reaction, CFD. 


\section{Introduction}

It is well known that circulating fluidized bed (CFB) is an important technology with significant industrial applications for gas-phase catalytic reacting system (Wang et al, [27]; Kunni and Levenspiel, [15]). Despite the wide use of this technology, the opportunity to improve and to reduce the risk of scaling up CFB system using computational fluid dynamics (CFD) is significant. However, the use of reacting flow Navier-Stoke based CFD to simulate CFB process is still very far from being routine. The difficulties arise due to the needs to describe the fluid dynamics associated not only of the gas-phase but also the flowing solid particulates that perform catalytic reaction. Accurate description of the dynamic for the solid flow is needed to predict the solid void fraction such that active site concentration of the catalyst can be accurately determined to calculate reaction rates in the reactor. Because of the complexity of multiphase flow theory, it appears that the CFD based method is still insufficient to provide accurate prediction of solid fraction profile (Mao, [19]; Mao et al, [20, 21]; Das et al, [6, 7]).

An alternative to the CFD reacting flow approach is to consider a more empirical engineering reactor model for gas-solid two-phase flow. This approach makes use of solid flow information based on some experimental data or published data (Kruse et al, [13]; Kruse and Werther, [14]; Abba et al, [1]). Review of the many available models, however, show that fundamental equations such as mass balance, momentum and energy balances, and assumptions of boundary condition used are not adequately described (Abba et al, [1]). In addition, numerical methods used in these models may result in numerical instability that render the prediction to be questionable.

In this work, an advanced gas-solid two-phase engineering reactor (AGS2D) model has been developed for flow, mass and heat transfer and reaction in the riser reactor of a circulating fluidized bed system. As in the conventional engineering CFB models, this approach will still use solid velocity and density profiles that could be determined experimentally or from published data. The current engineering model is equivalent to the two-fluid dynamic model for multiphase flow (Gidaspow, [11]; Mao et al, [20]). Velocity profile in the twofluid dynamic model is solved based on momentum equations without simplification, while velocity profile in the current AGS2D model is solved based on mass balance and velocity profiles. These profiles can be obtained from published data (Rhodes et al, [25]; Du et al, [8]) or cold flow experiment. Conceptually, this model can be used to scale up CFB reacting system from a pilot demonstration unit (PDU) and cold flow experimental data at various scale where data for gas and solid velocity profiles (Ug and Us) and solid void fraction and $\varepsilon_{\mathrm{s}}$ profiles are obtained. The kinetics can in principle be determined from experimental data or using a detailed elementary reaction based approach such as used by fundamental kinetic modeling approach (Tirtowidjojo and Pollard, [26]). However, the known kinetics for catalytic decomposition of ethylbenzene (EB) to styrene is considered here for illustration of AGS2D model utility. 


\section{Model development}

\subsection{Governing equations for both mass and energy balance}

Equations $1 \mathrm{a}, 1 \mathrm{~b}$ and $1 \mathrm{c}$ are governing equations for gas species concentration, gas temperature and solid temperature. Equations $2 \mathrm{a}$ and $2 \mathrm{~b}$ govern gas pressure and the last gas species concentration based on ideal equation of state, respectively. Equations 1 are solved based on an upwinding numerical scheme. As described above, the velocity profile used in Equations $2 \mathrm{a}$ is known. Heat transfer between gas and solids is coupled by heat transfer coefficient, $\mathrm{h}$, and temperature difference $T_{s}-T_{g}$. In the present case, $\mathrm{h}$ is considered to be infinite such that gas and solid have the same temperature.

$$
\begin{gathered}
\frac{\partial\left(\alpha_{g} C_{g, i}\right)}{\partial t}+\frac{\partial\left(\alpha_{g} u_{g} C_{g, i}\right)}{\partial z}=\frac{\partial}{\partial z}\left(D_{g, z} \alpha_{g} \frac{\partial C_{g, i}}{\partial z}\right)+\frac{1}{r} \frac{\partial}{\partial z}\left(D_{g, r} r \alpha_{g} \frac{\partial C_{g, i}}{\partial r}\right)+s_{g, i} \\
\frac{\partial\left(\rho_{g} \alpha_{g} C_{p, g} T_{g}\right)}{\partial t}+\frac{\partial\left(\rho_{g} \alpha_{g} C_{p, g} u_{g} T_{g}\right)}{\partial z}=\frac{\partial}{\partial z}\left(\lambda_{g, z} \alpha_{g} \frac{\partial T_{g}}{\partial z}\right)+\frac{1}{r} \frac{\partial}{\partial z}\left(\lambda_{g, r} r \alpha_{g} \frac{\partial T_{g}}{\partial r}\right)+s_{T, g}+h\left(T_{s}-T_{g}\right) \\
\frac{\partial\left(\rho_{s} \alpha_{s} C_{p, s} T_{s}\right)}{\partial t}+\frac{\partial\left(\rho_{s} \alpha_{s} C_{p, s} u_{s} T_{s}\right)}{\partial z}=\frac{\partial}{\partial z}\left(\lambda_{s, z} \alpha_{s} \frac{\partial T_{s}}{\partial z}\right)+\frac{1}{r} \frac{\partial}{\partial z}\left(\lambda_{s, r} r \alpha_{s} \frac{\partial T_{s}}{\partial r}\right)+s_{T, s}-h\left(T_{s}-T_{g}\right)
\end{gathered}
$$

Equations $1 \mathrm{a}, 1 \mathrm{~b}$ and $1 \mathrm{c}$ are written in a general conservation form to account for changing gas and solid volume fractions from along reactor height. However, in a fully developed zone at the middle of a riser reactor, for example, the $\alpha_{\mathrm{s}}$ is approximately constant, and many times this is typically assumed (Abba et al [1]) in the formulation. In the present work, we consider the most general case where solid flow is different from gas flow and dispersion and heat conduction for gas and solid phases. Mass density of a gas mixture is a function of axial location because both temperature and pressure change axially with development of endothermic or exothermic reactions. Thus, mixture gas mass density should be inside the derivative, rather than outside of the derivative as typically assumed (Abba et al, [1]).

$$
\begin{gathered}
\frac{d p_{g}}{d z}=-\frac{d}{d z}\left(\rho_{s} \alpha_{s} u_{s} u_{s}\right)-\rho_{s} \alpha_{s} g \\
C_{g, 1}=\frac{p_{g}}{R_{g} T}-\sum_{i=2}^{M} C_{g, i}
\end{gathered}
$$

Radial Peclet number, $P e_{r}$, is defined from radial dispersion coefficient in Equation 2c, while the Axial Peclet number, Pez, is defined from axial dispersion coefficient in Equation 2d. The influence of axial dispersion is ignored here due to the overwhelming convection. The source term, Equation 2e, is a function of gas-phase and catalytic reactions. Influence of radial gas velocity profile $(n)$, radial solid volume fraction $(f)$ and radial gas Peclet number $\left(P e_{r}\right)$ on EB conversion and Styrene selectivity will be assessed. The parameter $q$ is fixed at 2 or 3 (see Figure 1) due to Rhodes et al [25].

$$
P e_{r}=\frac{u_{\text {avg }} R}{D_{g, r}}
$$




$$
\begin{gathered}
P e_{z}=\frac{u_{a v g} R}{D_{g, z}} \\
S_{g, i}=\rho_{p}\left(1-\alpha_{g}\right) r_{i, c a t}+\alpha_{g} r_{i, \text { thermal }}
\end{gathered}
$$

\subsection{A hybrid of engineering gas-solid two-fluid model}

In this work, pressure drop for momentum balance due to solid acceleration and gravitational force are considered since pressure has a direct influence on reaction rates. Energy balances for heterogeneous system are also considered because temperature plays a key role in both gas and catalytic reaction rates. However, traditional reactor models (Abba, et al [1]) typically assume that both solid volume fraction and mixture gas mass density are fixed. The AGS2D model can directly make use of available velocity and solid fraction. Despite available velocity and solid volume fraction, literature search indicates that there has not been any attempt of directly coupling this flow information with heterogeneous reaction in a CFB or riser reactor model to evaluate and scale up riser reactor or CFB in general.

The gas phase and solid phase mass balances are calculated from radial profiles as shown in Equations 3a, 3b and 3c.

$$
\begin{gathered}
\dot{m}_{g}=\rho_{g, a v g} \alpha_{g, a v g} u_{g, a v g} A=\int_{0}^{R} \rho_{g} \alpha_{g} u_{g} \pi r d r \\
\dot{m}_{s}=\rho_{s} \alpha_{s, a v g} u_{s, a v g} A=\int_{0}^{R} \rho_{s} \alpha_{s} u_{s} \pi r d r \\
\alpha_{g, a v g}+\alpha_{s, a v g}=1
\end{gathered}
$$

Equation $4 \mathrm{a}$ describes average variables for gas mixture mass density, $\rho_{g, a v g}$, gas void fraction, $\alpha_{g, a v g}$, gas velocity, $u_{g, a v g}$, solid void fraction, $\alpha_{s, a v g}$, solid velocity, $u_{s, a v g}$, gas pressure, $p_{g, a v g}$, and temperature, $T_{a v g .}$. Since $\alpha_{s, a v g}$ is typically larger in the bottom acceleration region and top deceleration region and lowest in the middle fully developed region, fixed mass flow rate requires that the axial average solid velocity vary accordingly as described in Equation $3 \mathrm{~b}$.

$$
\phi_{\text {avg }}=\frac{\int_{0}^{R} \phi \pi r d r}{\pi R^{2}}
$$

Ideal gas equation of state is utilized in the present work as shown in Equation $4 \mathrm{~b}$.

$$
\rho_{\text {avg }}=\frac{\int_{0}^{R} \rho_{g} \pi r d r}{\pi R^{2}}=\frac{p_{a v g}}{R T_{a v g}}
$$

Profiles for gas velocity in Equation 5a can be taken from Martin et al [23] and Derouin et al [7]. In a riser, index $n$ may be around $1 / 7$ and less than 1.0 because of turbulence (Bird et al, [4]). 

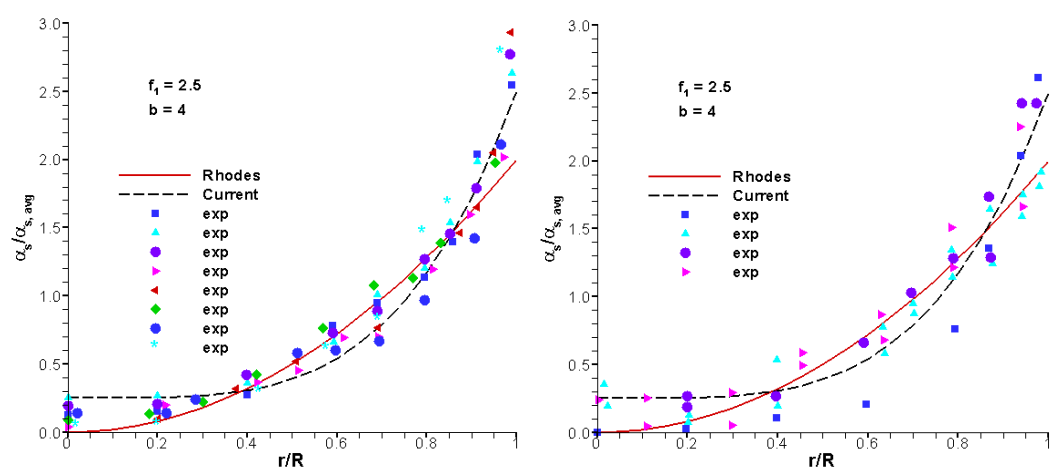

Figure 1: $\quad$ Solid volume fraction radial profile (Rhodes et al, [25]).

$$
u_{g}=\frac{u_{\text {avg }}}{\alpha_{g, a v g}}\left[\frac{3 n+1}{n+1}\right]\left[1-\left(\frac{r}{R}\right)^{\frac{n+1}{n}}\right]
$$

Rhodes et al [25] provided solid volume fraction radial profile as show in Equation 6a. Note that this equation tends to under predict the exp data at the center and close to the wall as shown in Figure 1. The AGS2D model can use either correlation equations or discrete data. The extension of Equation $6 \mathrm{a}$ is shown in Equation $6 \mathrm{~b}$ with four parameters, $\alpha_{s, 0}, \alpha_{s, 1}, a$, and $b$. Rhodes et al [25] analyzed that plot shape, $b$ to be in the range of 1 and 3 .

$$
\begin{gathered}
\frac{\alpha_{s}}{\alpha_{s, \text { avg }}}=2\left(\frac{r}{R}\right)^{2} \\
\frac{\alpha_{s}-\alpha_{s, 0}}{\alpha_{s, 1}-\alpha_{s, 0}}=a\left(\frac{r}{R}\right)^{b}
\end{gathered}
$$

Average solid volume fraction is defined in Equation 6c. The relationship among average solid volume fraction and parameters is listed in Equation 6d when $a$ is equal to 1 .

$$
\begin{gathered}
\int_{0}^{R} 2 \pi \alpha_{s} r d r=\pi R^{2} \bar{\alpha}_{s} \\
\bar{\alpha}_{s}=\frac{b}{b+2} \alpha_{s, 0}+\frac{2}{b+2} \alpha_{s, 1}
\end{gathered}
$$

Solid volume fractions at both wall $\left(\alpha_{s, 1}\right)$ and core center $\left(\alpha_{s, 0}\right)$ can be related by "f" in Equation 6g. Thus, two-parameter correlation equation for solid volume fraction is shown in Equations $6 \mathrm{~h}$ and $6 \mathrm{i}$. It is interesting to note from experimental data in Figure 2 that " $b$ " is in order of 4 and " $f$ " is in order of 10 or even 20 .

$$
\begin{gathered}
\alpha_{s, 1}=f_{1} \bar{\alpha}_{s} \\
\alpha_{s, 0}=\frac{b+2-2 f_{1} \bar{\alpha}_{s}}{b}
\end{gathered}
$$




$$
\begin{gathered}
f=\frac{\alpha_{s, 1}}{\alpha_{s, 0}}=\frac{b f_{1}}{b+2-2 f_{1}} \\
\frac{\alpha_{s}}{\alpha_{s, \text { avg }}}=\frac{b+2}{b+2 f}\left[1+(f-1)\left(\frac{r}{R}\right)^{b}\right] \\
\frac{1-\alpha_{g}}{1-\alpha_{g, \text { avg }}}=\frac{q+2}{q+2 f}\left[1+(f-1)\left(\frac{r}{R}\right)^{q}\right]
\end{gathered}
$$

Note that Equation $6 \mathrm{~h}$ and $6 \mathrm{i}$ automatically average value when integrating gas velocity radial profile or radial solid void fraction.

\subsubsection{Axial average velocity profile for both gas phase and solid phase}

Axial profiles for average solid velocity and gas velocity in Equations $7 \mathrm{a}$ and $7 \mathrm{~b}$ can be calculated based on mass balance and axial average solid void fraction.

$$
\begin{gathered}
u_{s, a v g}=\frac{\dot{m}_{s}}{\rho_{s} \alpha_{s, a v g} A} \\
u_{g, a v g}=\frac{\dot{m}_{g}}{\rho_{g, a v g} \alpha_{g, a v g} A}
\end{gathered}
$$

Mass balance for both gas and solid two phases should be satisfied not only for reactor scale (whole cross radial section) based on Equations $7 \mathrm{a}$ and $7 \mathrm{~b}$, but also for each control volume cell.

Axial average solid void fraction can be obtained from pressure drop data or from cold flow experiments. Equation $7 \mathrm{c}$ describes the pressure drop on reactor scale and Equation $7 \mathrm{~d}$ is for pressure on each cell. Equation $7 \mathrm{e}$ shows the gas density as a function of temperature and species composition.

$$
\begin{gathered}
\frac{d p_{g, a v g}}{d z}=-\frac{d}{d z}\left(\rho_{s} \alpha_{s, a v g} u_{s, a v g} u_{s, a v g}\right)-\rho_{s} \alpha_{s, a v g} g \\
\frac{d p_{g}}{d z}=-\frac{d}{d z}\left(\rho_{s} \alpha_{s} u_{s} u_{s}\right)-\rho_{s} \alpha_{s} g \\
\rho_{g}=\frac{p_{g}}{R T \sum_{m=1}^{M} \frac{Y_{m}}{M_{m}}}
\end{gathered}
$$

\subsection{Reaction kinetics}

Reaction kinetics for EB reaction is taken from Ahari et al [2] as shown in Equations $8 \mathrm{a}$ to $8 \mathrm{~b}$. Kinetics parameters are shown in Table 1.

$$
\begin{aligned}
& \mathrm{C}_{6} \mathrm{H}_{5} \mathrm{CH}_{2} \mathrm{CH}_{3}(\mathrm{~EB}) \leftrightarrow \mathrm{C}_{6} \mathrm{H}_{5} \mathrm{CHCH}{ }_{2}(\mathrm{STY})+\mathrm{H}_{2} \\
& \mathrm{C}_{6} \mathrm{H}_{5} \mathrm{CH}_{2} \mathrm{CH}_{3}(\mathrm{~EB}) \rightarrow \mathrm{C}_{6} \mathrm{H}_{6}(\mathrm{BZ})+\mathrm{C}_{2} \mathrm{H}_{4} \\
& \mathrm{C}_{6} \mathrm{H}_{5} \mathrm{CH}_{2} \mathrm{CH}_{3}(\mathrm{~EB})+\mathrm{H}_{2} \rightarrow \mathrm{C}_{6} \mathrm{H}_{5} \mathrm{CH}_{3}(\mathrm{TOL})+\mathrm{CH}_{4}
\end{aligned}
$$


The species heat capacity, $C_{p}$, is calculated from Equation $8 \mathrm{c}$ and the corresponding constants are listed in Table 2. Heat of reaction is obtained from NIST database.

$$
\begin{aligned}
& r_{1}=k_{1}\left(P_{E B}-P_{S T Y} P_{H_{2}} / K_{E B}\right) \\
& r_{2}=k_{2} P_{E B} \\
& r_{3}=k_{3} P_{E B} P_{H_{2}} \\
& k_{i}=3600 \exp \left(A_{i}-E_{i} / R T\right) \\
& K_{E B}=\exp \left(\frac{-\Delta F}{R T}\right) \\
& \Delta F=122725.157-126.27 T-2.194 \times 10^{-3} T^{2}
\end{aligned}
$$

Table 1: $\quad$ Kinetic parameters for dehydrogenation catalyst reactions.

\begin{tabular}{lcc}
\hline Reaction No. & A & E $(\mathrm{kJ} / \mathrm{kmol})$ \\
\hline 1. STY & 0.02 & $8.071 \mathrm{E} 4$ \\
2. BZ & 19.4 & $25.0 \mathrm{E} 4$ \\
3. TOL & 0.3 & $8.73 \mathrm{E} 4$ \\
\hline
\end{tabular}

$$
C_{p}=A+B T+C T^{2}+\frac{D}{T^{2}}
$$

Table 2: $\quad$ Coefficients for thermal capacity.

\begin{tabular}{|c|c|c|c|c|}
\hline Species name & A & B & C & D \\
\hline EB & $1.314 \mathrm{E}+01$ & $9.539 \mathrm{E}-02$ & $-3.248 \mathrm{E}-05$ & -691200 \\
\hline Sty & $1.800 \mathrm{E}+01$ & $7.150 \mathrm{E}-02$ & $-2.150 \mathrm{E}-05$ & -917000 \\
\hline H2 & $7.130 \mathrm{E}+00$ & $-7.120 \mathrm{E}-04$ & $7.570 \mathrm{E}-07$ & -2900 \\
\hline BZ & $7.280 \mathrm{E}+00$ & $6.810 \mathrm{E}-02$ & $-2.390 \mathrm{E}-05$ & -543000 \\
\hline Ethylene & $3.480 \mathrm{E}+00$ & $2.790 \mathrm{E}-02$ & $-8.730 \mathrm{E}-06$ & -62400 \\
\hline Toluene & $1.060 \mathrm{E}+01$ & $8.050 \mathrm{E}-02$ & $-2.740 \mathrm{E}-05$ & -568000 \\
\hline Methane & $6.910 \mathrm{E}-01$ & $2.260 \mathrm{E}-02$ & $-6.320 \mathrm{E}-06$ & 141000 \\
\hline N2 & $6.760 \mathrm{E}+00$ & $6.060 \mathrm{E}-04$ & $1.300 \mathrm{E}-07$ & 0 \\
\hline
\end{tabular}

\subsection{Boundary and initial conditions}

Initially, the riser is filled with nitrogen only. Dirichlet boundary condition or fixed number is used at the bottom inlet section, Neumann boundary condition is used at the top outlet riser, symmetric boundary condition is used at the core center and wall boundary condition is used at the riser wall.

\subsection{Numerical scheme}

Equations 1a, 1b and 1d can be written in a compact conservation in Equation 9a based on numerical flux. $E$ and $F$ are convection fluxes along $\mathrm{z}$ and $\mathrm{x}$ directions, respectively. $E_{v}$ and $F_{v}$ are diffusion or heat conduction flux along $\mathrm{z}$ and $\mathrm{x}$ directions, respectively. 
Second order term as diffusion or heat conduction are discretized with central-difference scheme. But for convection term, Patankar [24] found centraldifference scheme is not stable and developed a power and mixed scheme. Liou $[17,18]$ developed a AUSM and AUSM+ scheme for all speeds, Edwards [9] developed a low-diffusion flux-splitting scheme (LDFSS). Both AUSM and LDFSS are similar based on flux splitting with low diffusion. Mao et al [20, 21] developed LDFSS and AUSM for gas-solid two-phase flow and reaction. Here, first order upwinding scheme is utilized in Equation 9c for steady state results. Central-difference scheme is shown in Equation 9d.

$$
\begin{gathered}
\frac{\partial \phi}{\partial \tau}+\frac{\partial\left(E-E_{v}\right)}{\partial z}+\frac{\partial\left(F-F_{v}\right)}{\partial x}=0 \\
E=u \phi \quad E_{v}=\Gamma_{z} \frac{\partial \phi}{\partial z} \\
F=0 \quad F_{v}=\Gamma_{x} \frac{\partial \phi}{\partial x} \\
E_{i+1 / 2}=(u \phi)_{i+1 / 2}=\left\{\begin{array}{l}
(u \phi)_{i}, \text { if } u \geq 0 \\
(u \phi)_{i+1}, \text { if } u<0
\end{array}\right. \\
E_{i+1 / 2}=(u \phi)_{i+1 / 2}=\frac{(u \phi)_{i+1}+(u \phi)_{i}}{2}
\end{gathered}
$$

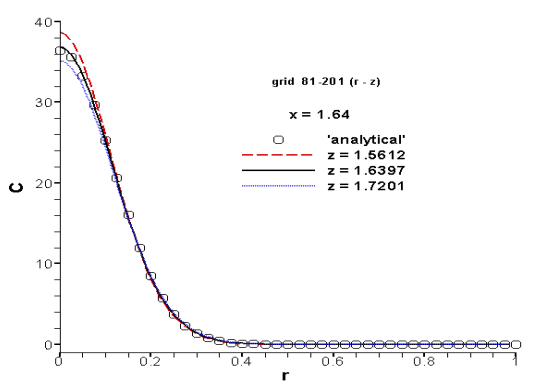

(a)

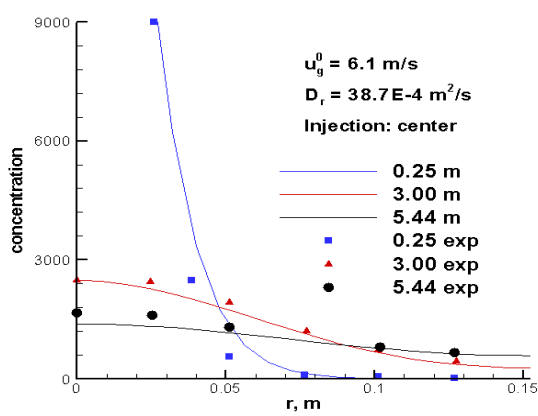

(b)

Figure 2: (a): Radial concentration profile; (b): Radial $-\mathrm{C}$ profiles (Bader et al, [3]).

\section{Results and discussions}

\subsection{Validation}

Comparison against analytical solution derived by Klinkenberg et al [12] shows good comparison at wide range of $P e_{r}$ for flat gas velocity (gas velocity is constant along radial direction) as shown in Figure 2a. Numerical method 
residual is found to be as small as 1.0e-9. Finally, a good comparison with experimental data from Bader et al [3] is obtained in Figure $2 b$.

The AGS2D model also compares favourably against the analytical solution for 1D flow and reaction without dispersion (Levenspiel, [16]) for both first and second order reaction kinetics.

\subsection{Influence of numerical scheme}

Central difference numerical scheme (CD) shows oscillation or unstable phenomena as shown in Figure $3 \mathrm{a}$, and in contrast simulation by upwinding numerical scheme (UW) is very stable also observed by Patankar [24]. Gas velocity is constant along radial direction and is $1.0 \mathrm{~m} / \mathrm{s}$. Inlet gas concentration may be unity or (1/a), where a is tracer injection radius.
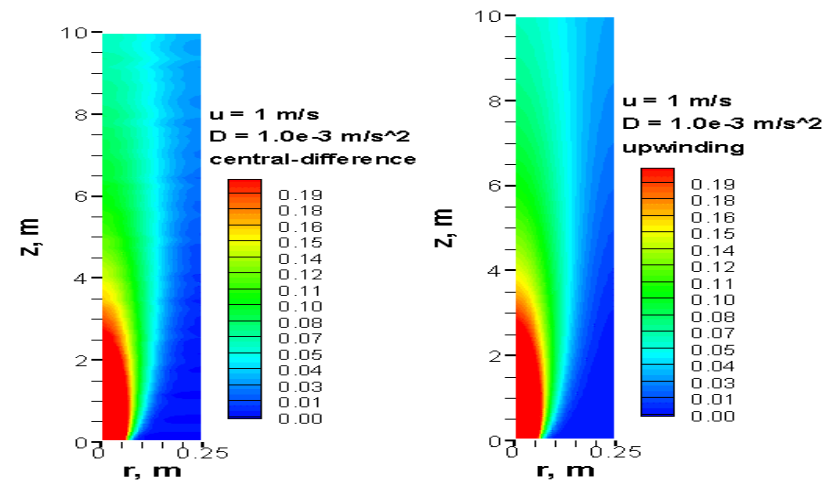

(a)

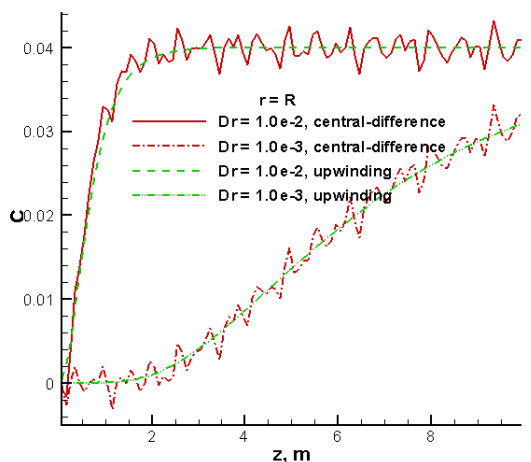

(b)

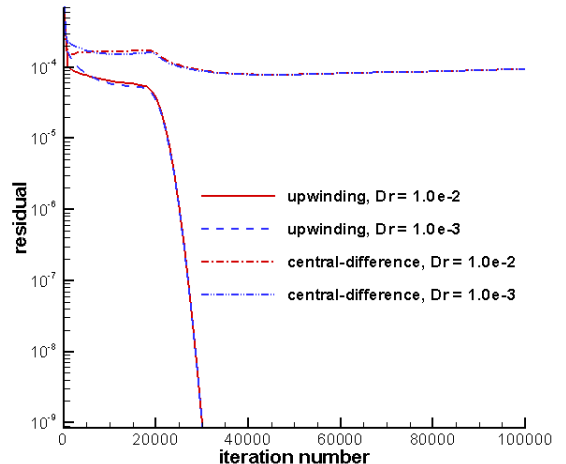

(c)

Figure 3: (a): C-contours by different numerical scheme using 21(r) by 101 (z) mesh; (b): Tracer-C close to the wall; (c): Error evolution.

When dispersion coefficient increases ten times larger from $1.0 \mathrm{E}-3$ to $1.0 \mathrm{E}-2$, oscillation still takes place with CD while not observed with UW. The fluctuation of $\mathrm{CD}$ predicted concentration particularly close to the wall depicted 
in Figure $3 \mathrm{~b}$ is so large that negative concentration predicted near the inlet of the reactor. To overcome this numerical instability problem the typical practice is to force the negative dimensionless concentration to be zero and "unity" when concentration is larger than the unity. While, this method may work for simple dispersion convection flow, it is difficult to conceive how CD will predict a reasonable result when reaction exists.

The numerical diffusion problems associated with UW has been solved by a low-diffusion flux-splitting scheme and advection upstream splitting method developed by Mao et al [20]. In addition, UW provides much faster convergence than $\mathrm{CD}$ as shown in Figure 3c.

\subsection{Influence of radial and axial solid volume fraction profile}

Figure 4a shows different axial solid volume fraction profiles considered. "case1 " uses a uniform distribution along axial direction, "case-2" and "case-3" profiles are taken from literature (Levenspiel, [16]), "case-4" corresponds to a step profile with same average solid volume fraction as "case-1". "case- 5 " has just as half of solid volume fraction as "case-1". Figure $4 \mathrm{~b}$ shows that solid profile has great influence on temperature profile as expected since the catalyst also provides heat input to the system.

Figures $4 \mathrm{c}$ and $4 \mathrm{~d}$ show that the axial solid fraction profile has some influence on EB conversion and Styrene selectivity even though total mass of solid is same (i.e. case 1 and 4) at Peclet number is 250. As can be seen in Figure 4c, EB conversion is lower in case 4 than in case 1 even though the total solid fraction in the reactor is the same. The model shows that the more uniform solid density profile gives higher conversion even though the end temperature point is very close as can be seen in figure $4 \mathrm{~b}$. Figure $4 \mathrm{c}$ also shows that a significant conversion can be achieved at lower riser height where the axial solid density is larger as in cases 2, 3, and 4 as compared to case 1

By decreasing solid density in the riser by half (compare case 5 and 1), EB conversion was predicted to drop while Styrene selectivity increased (see Figures 4d) as expected since the reaction rates also drop with lower catalyst in the riser. This is also confirmed by comparison of the more realistic solid profiles described by cases 2 and 3 . The model prediction clearly shows that both the solid hold up and profile in the reactor are important factors in the design of riser reactor for endothermic reaction where highest temperature is the most significant at the beginning of the riser reactor.

Note that the use of piece-wise linear function in cases 2-4 as an input to the AGS2D model demonstrate the robustness of the numerical solver used in this model.

\section{Conclusions}

An advanced hybrid of CFD and engineering reactor model in 2D model has been developed for gas-solid two-phase flow, heat transfer and reaction for the circulating fluidized bed riser. Mass balance, momentum balance and energy balance are considered for the coupling of two-phase flow and reaction. A robust 
numerical scheme, upwinding scheme, is used to solve the partial differential equations. The model and the numerical scheme are validated by comparison with analytical solution, experimental data, mass balance and residual check. The developed model has also been shown to accommodate various input from experimentally determined solid and gas velocity profiles and density. The model can be used to extract kinetics from pilot reactor and scale-up for production reactor. Sensitivity analysis shows that gas velocity, gas dispersion, and solid volume fraction has influence on reaction rate. The model shows also that catalyst profile inside the reactor is a critical parameter for reactor design.

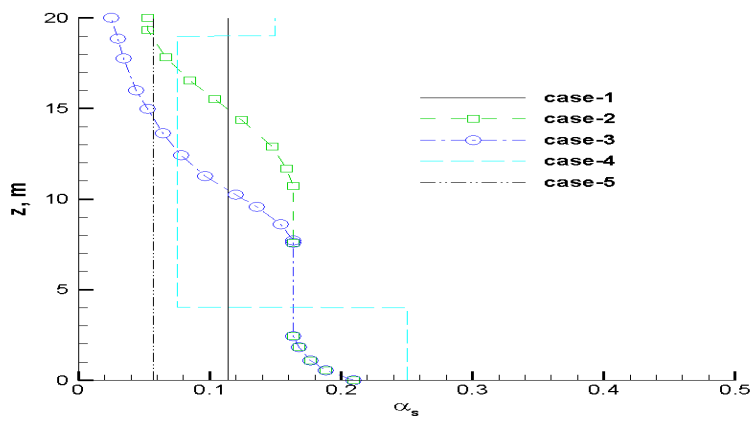

(a)

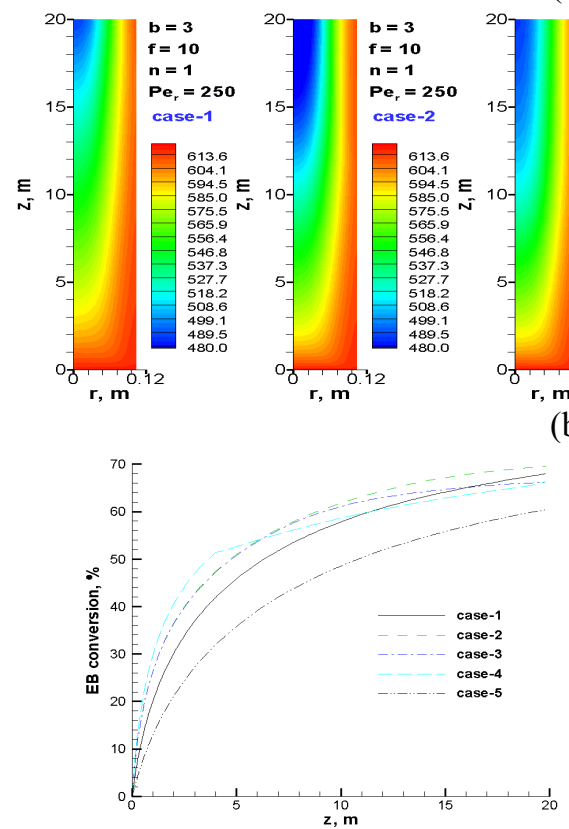

(c)

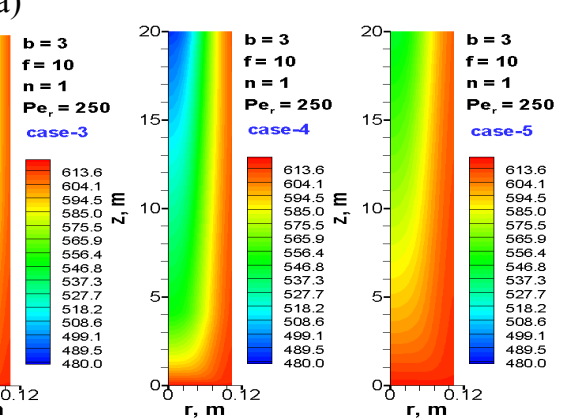

(b)

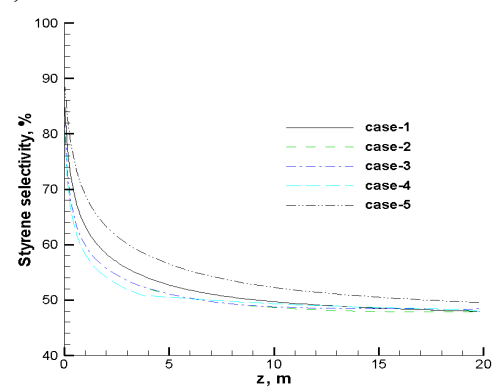

(d)

Figure 4: (a): Average axial solid volume fraction; (b): Temperature contours under different solid profiles; (c): Average EB conversion; (d): Average Styrene selectivity. 


\section{References}

[1] Abba, I.A., Grace, J.R., Bi, H.T. and Thompson, M.L. "Spanning the flow regimes: generic fluidized-bed reactor model", AIChE Journal, Vol 49, 1838-1848, 2003

[2] Ahari, J.S., Kakavand, M., Farshi, A. and Abedi, M.A.H. "Modeling of radial flow reactors of oxidative reheat process for production of Styrene monomer", Chem. Eng. Techno. Vol 27, p139-p145, 2004

[3] Bader, R., Findlay, J. and Knowlton, T.M. "Gas/solids flow patterns in a 30.5-cm-diameter circulating fluidized bed", Pergamon, Oxford, UK, Circulating Fluidized Bed Technology II Ed, 1988

[4] Bird, R.B., Stewart, W.E. and Lightfoot, E.N. "Transport Phenomena", John Wiley \& Sons, 1960

[5] Das, A.K., De Wilde, J., Heynderickx, G.J. and Marin, G.B. "CFD simulation of dilute phase gas-solid riser reactors: Part II - simultaneous adsorption of $\mathrm{SO}_{2}-\mathrm{NO}_{\mathrm{x}}$ from flue gas”, Chem. Eng. Sci. Vol 59, 187-200, 2004b

[6] Das, A.K., De Wilde, J., Heynderickx, G.J., Marin, G.B., Vierendeels, J. and Dick, E."CFD simulation of dilute phase gas-solid riser reactors: Part I - a new solution method and flow model validation", Chem. Eng. Sci. Vol 59, 167-186, 2004a

[7] Derouin, C., Nevicato, D., Forissier, M., Wild, G. and Bernard, J.R. "Hydrodynamics of riser units and their impact on FCC operation", Ind. Eng. Chem. Res. Vol 36, 4504-4515, 1997

[8] Du, B., Fan, L.S., Wei, F. And Warsito, W. "Gas and solids mixing in a turbulent fluidized bed", AIChE Journal, Vol 48, 1896-1909, 2002

[9] Edwards, J.R. "A low-diffusion flux-splitting scheme for Navier-Stokes calculations", Computers \& Fluids, Vol 26, 635-659, 1997

[10] Elnashaie, S.S.E.H., Abdallah, B.K., Elshishini, S.S., Alkohwaiter, S., Noureldeen, M.B. and Alsoudani, T. "On the link between intrinsic catalytic reactions kineics and the development of catalytic processes: Catalytic dehydrogenatin of ethylbenzene to styrene", Catalysis Today, Vol 64, 151-162, 2001

[11] Gidaspow, D. Multiphase flow and fluidization: Continuum and kinetic theory descriptions; Academic Press Inc. Boston, 1994

[12] Klinkenberg, A., Krajenbrink, H.J. and Lauwerier, H.A. "Diffusion in a fluid moving at uniform velocity in a tube", Industrial and Engineering Chemistry, Vol 45, 1202-1208, 1953

[13] Kruse, M., Schoenfelder, H., and Werther, J. "A two-dimensional model for gas mixing in the upper dilute zone of a circulating fluized bed", The Canadian Journal of Chemical Engineering, Vol 73, p620-634, 1995

[14] Kruse, M. and Werther, J. "2D gas and solids flow prediction in circulating fluidized beds based on suction probe and pressure profile measurements", Chem. Eng. Sci., Vol 34, p 185-203, 1995

[15] Kunni, D. and Levenspiel, O. "Fluidization Engineering", $2^{\text {nd }}$ ed. Butterworth-Heinemann, 1991 
[16] Levenspiel, O. "Chemical reaction engineering", John Wiley \& Sons, p449, 1999

[17] Liou, M.S. "A sequel to AUSM, Part II: AUSM+ up for all speeds", Journal of Computational Physics, Vol 214, 137-170, 2006

[18] Liou, M.S. "A sequel to AUSM", Journal of Computational Physics, Vol 214, 137-170, 1996

[19] Mao, D. "Particle flow, agglomeration, mixing, physical and chemical adsorption in circulating fluidized bed adsorbers", Dissertation, North Carolina State University, 2002

[20] Mao, D., Edwards, J,R., Kuznetsov, A.V. and Srivastava, R.K. "Threedimensional numerical simulation of a circulating fluidized bed reactor for multi-pollutant control", Chemical Engineering Science, Vol 59, 42794289, 2004

[21] Mao, D., Edwards, J.R., Kuznetsov, A.V. and Srivastava, "Transient gassolid and multi-pollutant control simulations in circulating fluidized bed absorbers", $16^{\text {th }}$ AIAA CFD conference, June 2003, Orlando, Florida, USA

[22] Mao, D., Edwards, J.R., Kuznetsov, A.V. and Srivastava, R. "A gas mixture/solids mixture model for particle flow, agglomeration, chemical and physical adsorption in circulating fluidized bed adsorbers", Chemical Engineering Science, Vol 59, 4279-4284, 2004

[23] Martin, M.P., Turlier, P. and Bernard, J.R. "Gas and solid behavior in cracking circulating fluidized beds", Powder Technology, Vol 70, p249258, 1992

[24] Patankar, S.V. "Numerical heat transfer and fluid flow", John Benjamins Publishing Co, 1980

[25] Rhodes, M., Zhou, S.H. and Benkreira, H. "Flow of dilute gas-particle suspensions", AIChE Journal, Vol 38, p 1913-1915, 1992

[26] Tirtowidjojo, M. and Pollard, R. "The influence of reactor pressure on rate-limiting factors and reaction pathways in MOVPE of GaAS", Journal of Crystal Growth, Vol 33, 420-438, 1989

[27] Wang, L., Shen, B.X. and Li, S.Z. "Model of fluidized catalytically cracked (FCC) gasoline photochemical desulfurization reactor", Energy \& Fuels, Vol 20, 1287-1293, 2006 